\title{
$h^{2} \mathrm{e}=\mathrm{F}^{\circ}$ \\ Internal library of the Celeida Tostes Studio for the Ceramic Arts
}

\section{Biblioteca interna do Espaço de Artes Cerâmicas Celeida Tostes}

\section{Marcos Roxo ${ }^{1}$, Yrvin Gomes ${ }^{2}$, Karine Corrêa ${ }^{3}$, Carlos Augusto Bittencourt ${ }^{4}$, Katia} Gorini $^{5}$, Andréa Borde ${ }^{6}$

${ }^{1}$ Graduação na Faculdade de Arquitetura e Urbanismo, Universidade Federal do Rio de Janeiro - 0000-0001-5893-6707

${ }^{2}$ Graduação na Faculdade de Arquitetura e Urbanismo, Universidade Federal do Rio de Janeiro - 0000-0002-0137-6208

${ }^{3}$ Graduação em Conservação e Restauração, Escola de Belas Artes, Universidade Federal do Rio de Janeiro - 0000-0001-8234-2079

${ }^{4}$ Graduação em Artes Visuais - Escultura, Escola de Belas Artes, Universidade Federal do Rio de Janeiro

${ }^{5}$ Departamento de Artes Visuais - Escultura, Escola de Belas Artes, Universidade Federal do Rio de Janeiro - 0000-0003-0120-792x

${ }^{6}$ Departamento de Análise e Representação da Forma, Faculdade de Arquitetura e Urbanismo, Universidade Federal do Rio de Janeiro - 0000-0002-0092-011X

marcos.roxo@fau.ufrj.br,gomesyrvin@gmail.com, karinepegui@gmail.com, arte.bittencourt@gmail.com, kcgorini@gmail.com, andreaborde@gmail.com

Recebido: 27/04/2021 Aceito: 29/04/2021 Publicado: 04/05/2021

DOI: 10.51919/revista_sh.v1i0.278

\begin{abstract}
This paper seeks to value the academic production of the Celeida Tostes Studio for the Ceramic Arts. Currently, a series of projects are being developed independently from each other every semester and in order to change this internal dynamic a documentation and dissemination system was proposed. It is a way to offer digital means by which students of a given semester can be in contact with the production that preceded them. Preliminary results show the capability of the studio to feed on experiments and knowledge that were produced in the past and let those impact the studio once again.
\end{abstract}

Keywords. Ceramic. Academic production. Knowledge dissemination.

Resumo. O presente trabalho busca a valorização da produção acadêmica do Espaço de Artes Cerâmicas Celeida Tostes por meio da modificação da sua dinâmica interna. $\mathrm{O}$ atual cenário do ateliê se configura pelo desenvolvimento corrente de projetos por parte dos discentes de forma independente, visto isso, se propôs a criação de um sistema de documentação e divulgação, a fim de oferecer um meio digital pelo qual os estudantes 
de dado período possam estar em contato com a produção que lhes precedeu. Os resultados preliminares mostram a capacidade desse espaço acadêmico de produção artística de se retroalimentar, ao permitir que o conhecimento gerado e as experimentações realizadas impactem o ateliê novamente.

Palavras-chave. Cerâmica. Produção acadêmica. Disseminação do conhecimento.

\section{Introdução}

A Oficina Integrada de Cerâmica, Espaço de Artes Cerâmicas Celeida Tostes é uma parceria entre a Escola de Belas Artes (EBA) e a Faculdade de Arquitetura e Urbanismo (FAU), ambas da Universidade Federal do Rio de Janeiro (UFRJ). E surge enquanto "Centro Integrado de Cerâmica EBA/FAU-UFRJ" em 1989, sob a concepção da Professora Celeida Moraes Tostes. Nele são ministradas, dentre outras, as disciplinas "cerâmica" e "cerâmica aplicada à arquitetura" ambas no foco deste trabalho, e nas quais em cada semestre inúmeros projetos são produzidos de forma independente, isso ocorre sem que a produção de um semestre impacte significativamente a produção dos períodos subsequentes, havendo somente procuras pontuais pela produção prévia. O objeto central aqui trabalhado, apesar de estarmos tratando de um ateliê de cerâmica, não são os objetos cerâmicos em si, mas sim a produção textual e iconográfica gerada a partir destes.

O projeto busca celebrar a produção interna do Ateliê, assim como tornar a mesma disponível para consultas futuras, com a intenção de fazer circular o conhecimento produzido internamente e compila-lo em uma biblioteca interna de livre acesso que fará com que progressivamente o trabalho prévio contribua de forma ativa para $o$ desenvolvimento geral dos discentes, criando um acervo vivo, que constantemente se atualiza e cresce.

Como objetivo deste artigo buscamos destrinchar o processo de criação do projeto. Evidenciamos, assim, as etapas percorridas desde a fundamentação teórica até a criação de páginas em mídias digitais.

\section{Sistema de documentação}

O projeto se dá em um ateliê universitário, onde se propõe a documentação, catalogação e exposição da sua produção interna, portanto, buscamos um embasamento coerente e parâmetros a serem seguidos. De encontro com os objetivos almejados e ações empregadas está a definição de "Sistemas de Documentação Museológica" de Helena Dodd Ferrez:

\footnotetext{
"Objetivos: conservar os itens da coleção; maximizar o acesso aos itens; maximizar o uso da informação contida nos itens.

Função: estabelecer contato efetivo entre as fontes de informação (itens) e os usuários, isto é, fazer com que estes, através de informação relevante, transformem suas estruturas cognitivas ou os conjuntos de conhecimento acumulado.
} 
Componentes: Entradas: seleção; aquisição. Organização e Controle: registro; número de identificação/ marcação; armazenagem/ localização; classificação/ catalogação; indexação. Saídas: recuperação; disseminação.” (FERREZ, 1994, p. 68)

Portanto, os passos realizados no Ateliê se aproximam das linhas gerais acima apresentadas. A coleta e guarda dos trabalhos teóricos produzidos no Espaço de Artes Cerâmicas garante a conservação da memória do que ali foi produzido e estudado, e ainda a organização destes em um acervo interno permite acesso ao público e possibilita a divulgação de um trabalho acadêmico que antes ficava estagnado ou invisibilizado.

Da mesma forma, no que diz respeito a sua função, o projeto Biblioteca Interna busca aproximar o corpo discente das disciplinas ministradas no Ateliê com a produção prévia, ao mesmo passo que torna essa produção pública.

Quanto aos componentes, a "entrada" a este acervo se dá pela própria produção dos estudantes e seleção dos trabalhos; a "organização e controle" se dá a partir dos dados que acreditamos pertinentes ao tipo de catalogação. E por fim, acredita-se que a sua "saída" ocorrerá de forma fluída, pela disseminação desses trabalhos nas redes sociais do Espaço de Artes Cerâmicas e pelas ferramentas virtuais onde se concederá acesso aos discentes.

Fundamentado o projeto foi necessário pensar na organização interna e para tanto “estabelecer um sistema de documentação apropriado para o acervo (...), baseando-se em estruturas técnicas gerais e especializadas, bem como estabelecendo uma série de convenções" (CAMARGO-MORO, 1986, p. 37).

\section{Organização e disseminação}

Após a coleta dos trabalhos produzidos no Ateliê até o momento foi necessário exercer um processo curatorial, onde cada um dos trabalhos foi analisado individualmente, sendo selecionados aqueles que possuíam um bom desenvolvimento textual, acerca de sua produção cerâmica, agregado a um repertório de imagens que ilustrassem o seu processo. Tais aspectos foram considerados uma vez que tratamos de um acervo acadêmico que tem como intuito ensinar e inspirar sobre o processo de fazer cerâmico, então não caberia somente averiguar o produto final mas sim se aquele caderno de projeto tem o potencial de servir como referência ao corpo social do Ateliê.

Analisada a pertinência de cada trabalho ao Espaço de Artes Cerâmicas foi criado um sistema de catalogação interna, na ferramenta Excel, onde os dados individuais foram inseridos de forma a criar uma base de dados para o controle e futura consulta.

A base de dados é composta pelos dados considerados pertinentes ao projeto, constam: imagem do projeto; período de produção; nome do autor; autorização para divulgação pública do trabalho; classificação do projeto; e-mail e identificação do autor. 


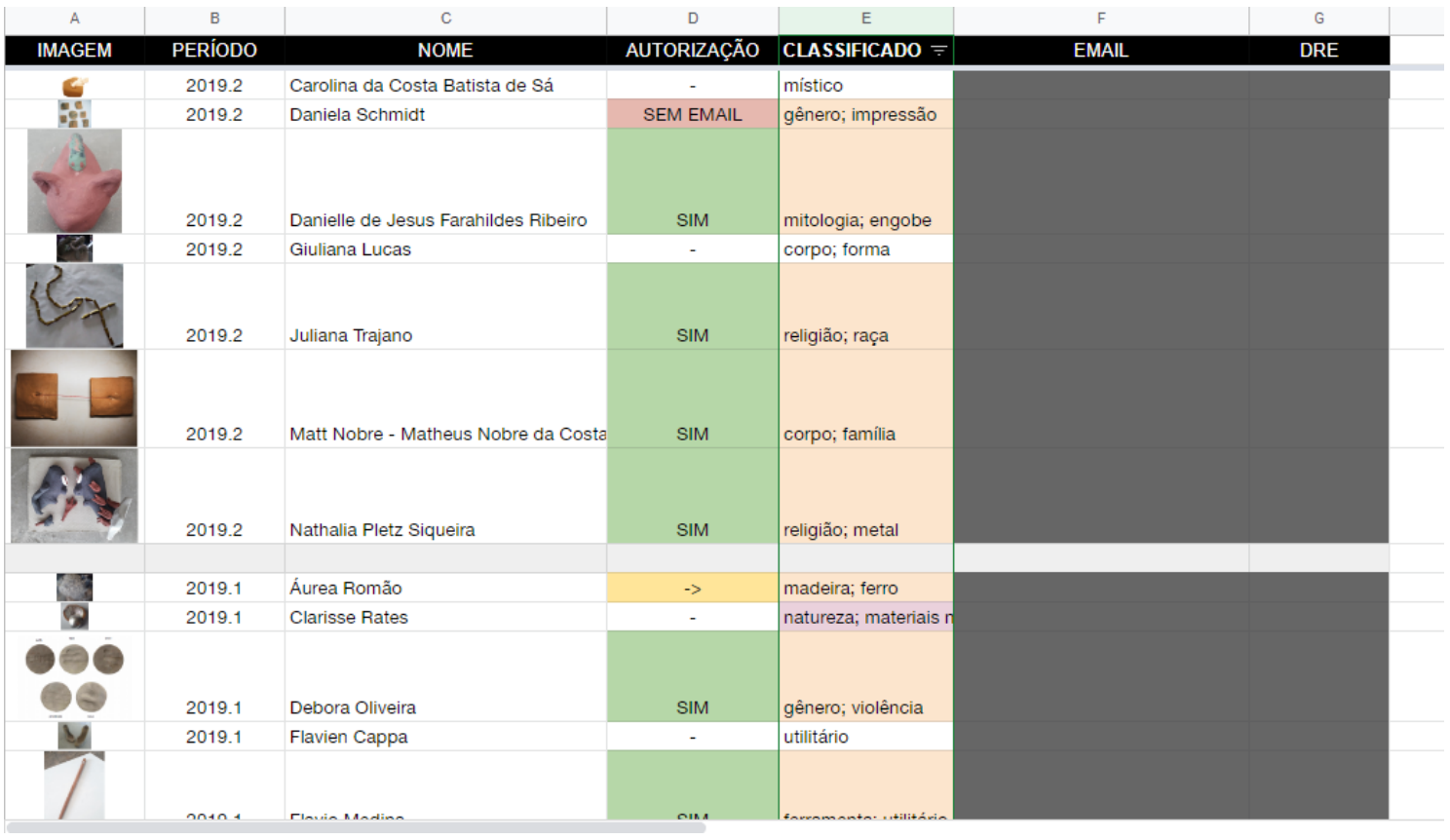

Figura 1. Base de dados da Biblioteca, criada na ferramenta Excel, com as informações de todos os projetos já analisados.

Na base de dados constam todos os projetos analisados, e não só os selecionados. Para a classificação foram criadas diversas categorias de modo a criar aproximações entre as diferentes produções: azulejo; cidade; ciência; cobogó; composição; corpo; engobe; ensino; escala; estrutura; família; ferramenta; ferro; forma; gênero; impressão; natureza; lixo; madeira; materiais não convencionais; metal; mineralização; místico; mitologia; mobiliário; música; performance; pintura; raça; religião; técnica; tecnologia; tijolo; utilitário; violência.

Catalogados todos os trabalhos analisados até então partimos para a etapa seguinte, a criação dos meios de divulgação deste acervo. Optamos por duas formas de divulgação distintas: a primeira como divulgação da iconografia dos trabalhos, na rede social Instagram, com intuito de uma dispersão mais rápida da produção interna em uma ferramenta de amplo acesso onde se conseguiria atingir tanto ao corpo social do Ateliê quanto ao público externo. 

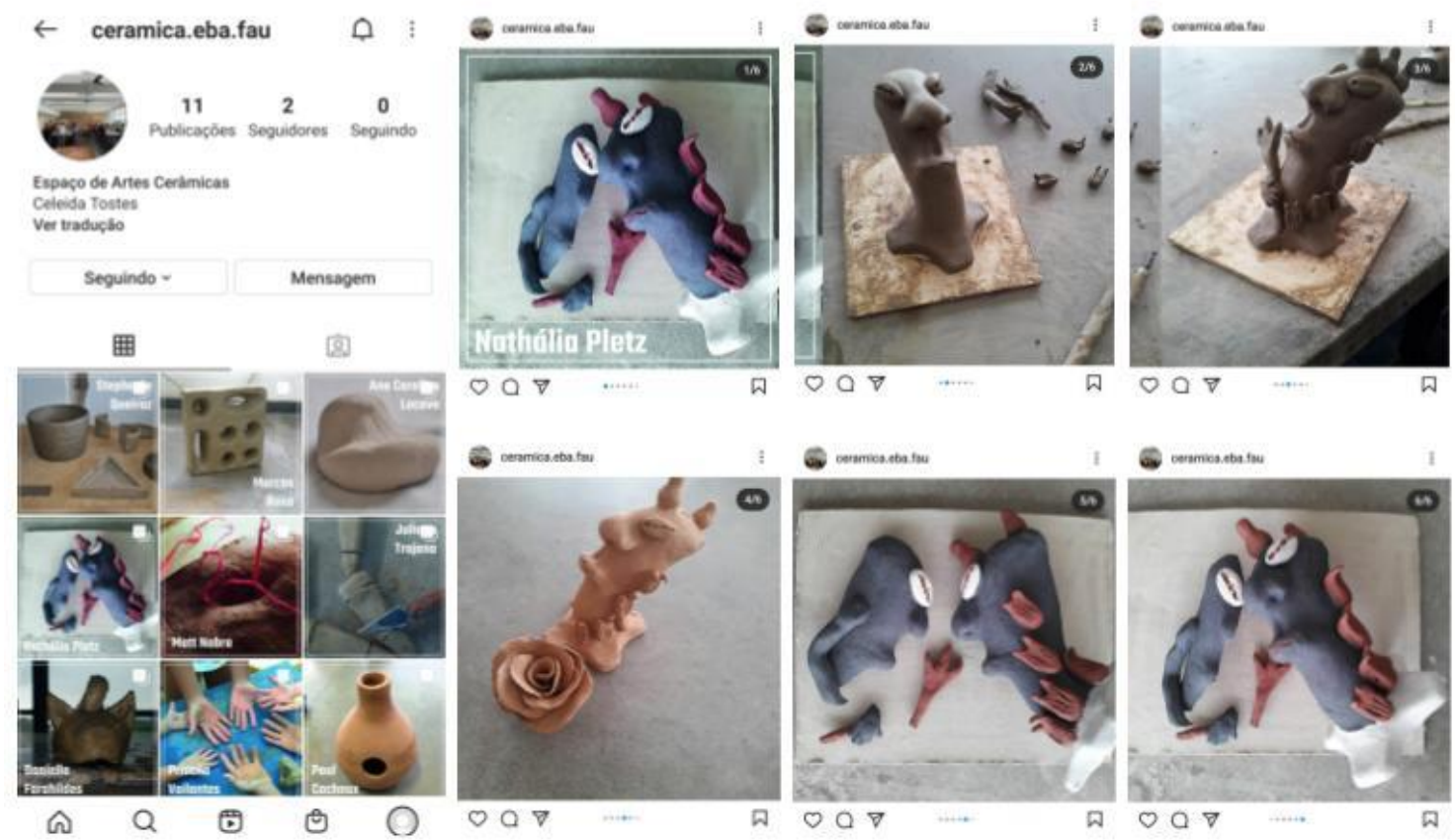

Figura 2. Página desenvolvida para o Espaço de Artes Cerâmicas Celeida Tostes no Instagram.

A rede social permite inúmeras postagens e um total de até dez fotos por postagem, dessa forma foi pensado em publicar as obras de cada estudantes individualmente e dentro dessa mesma publicação mostrar o desenvolvimento do trabalho por meio de múltiplas imagens. O usuário, então, teria conhecimento sobre o processo cerâmico e não somente sobre o produto final.

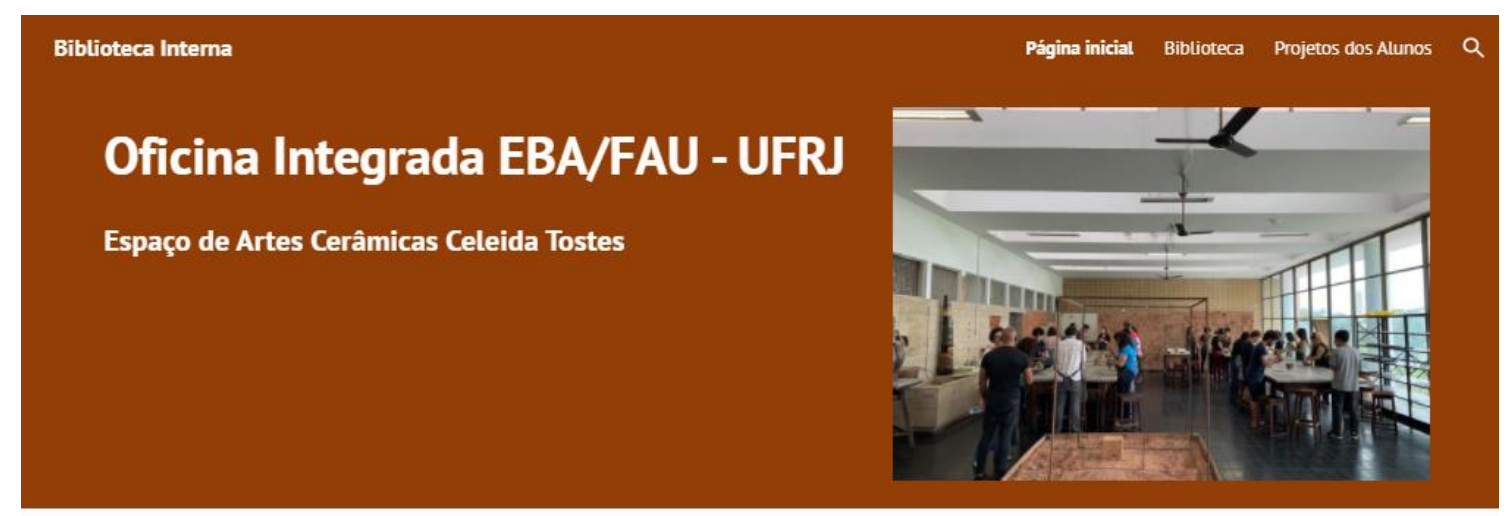

Biblioteca Interna dos trabalhos dos alunos do Espaço de Artes Cerâmicas Celeida Tostes. Desenvolvidos nas disciplinas Cerâmica I, Cerâmica II, Cerâmica aplicada a Arquitetura I e Cerâmica aplicada a Arquitetura II.

Laboratório de Cerâmica FAU UFRJ - Coordenação Andrea Borde

Laboratório LAB01 / EBA UFRJ - Coordenação Katia Gorini e Ana Cecília MacDowell

Figura 3. Página inicial desenvolvida para o Espaço de Artes Cerâmicas Celeida Tostes no Google Sites. 
A segunda forma de divulgação pensada foi a criação de um Google Site, este teria como foco somente os alunos das disciplinas "Cerâmica" e "Cerâmica aplicada à arquitetura", nela os alunos não só teriam acesso a iconografia do trabalho, mas sim ao trabalho em sua forma íntegra, onde podem encontrar a produção textual referente aos projetos e ao conjunto iconográfico mais completo, tendo sido editado somente os dados pessoais dos estudantes.

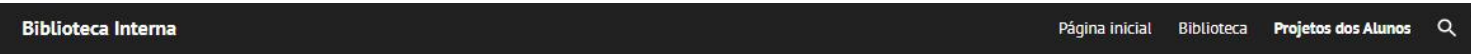

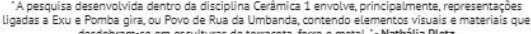
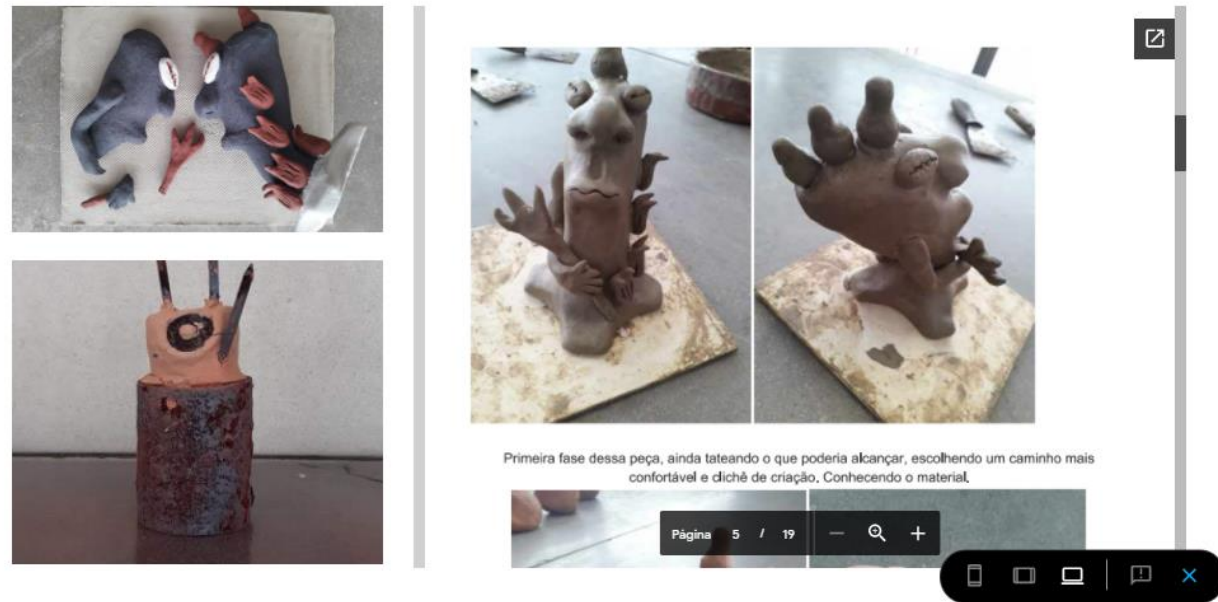

Figura 4. Iconografia e produção textual da aluna Nathália Pletz na página desenvolvida para o Espaço de Artes Cerâmicas Celeida Tostes no Google Sites.

\section{Considerações Finais}

Em suma, o artigo tem a intenção de iniciar o diálogo sobre a produção cerâmica, no que tange ao seu alcance, tanto no meio acadêmico quanto fora deste, busca-se evitar que o conhecimento produzido se restrinja ao tempo e ao espaço em que foram produzidos.

O projeto se encontra em andamento e acredita-se que o seu real potencial será atingido com o desenvolvimento do projeto a longo prazo, quando uma base de dados farta puder ser ofertada. Isso se dará com a intensa busca e catalogação por trabalhos preexistentes, e ainda pela futura contribuição e parceria daqueles que virão a passar pelo Ateliê.

\section{Financiamento}

O presente trabalho foi realizado com apoio do Programa de Bolsas de Iniciação Artística e Cultural - PIBIAC/UFRJ - N 37 / 2020

\section{Referências bibliográficas}

CAMARGO-MORO, F. Museus: aquisição-documentação. Rio de Janeiro: Livraria Eça, 1986. 
FERREZ, H. D. Documentação museológica: teoria para uma boa prática. Estudos de Museologia. Rio de Janeiro: Ministério da Cultura, Instituto do Patrimônio Histórico e Artístico Nacional. Departamento de Promoção, 1994. p. 65--74 (Cadernos de Ensaios 2).

SILVA, R.; COSTA, M. L.; MIRANDA, L; Á. R. Celeida Tostes. FUNARTE. Rio de Janeiro: 2017. 